\title{
ISSUES IN EFFECTIVE TEACHING LEARNING IN TOURISM EDUCATION
}

\author{
Toney. K. Thomas*
}

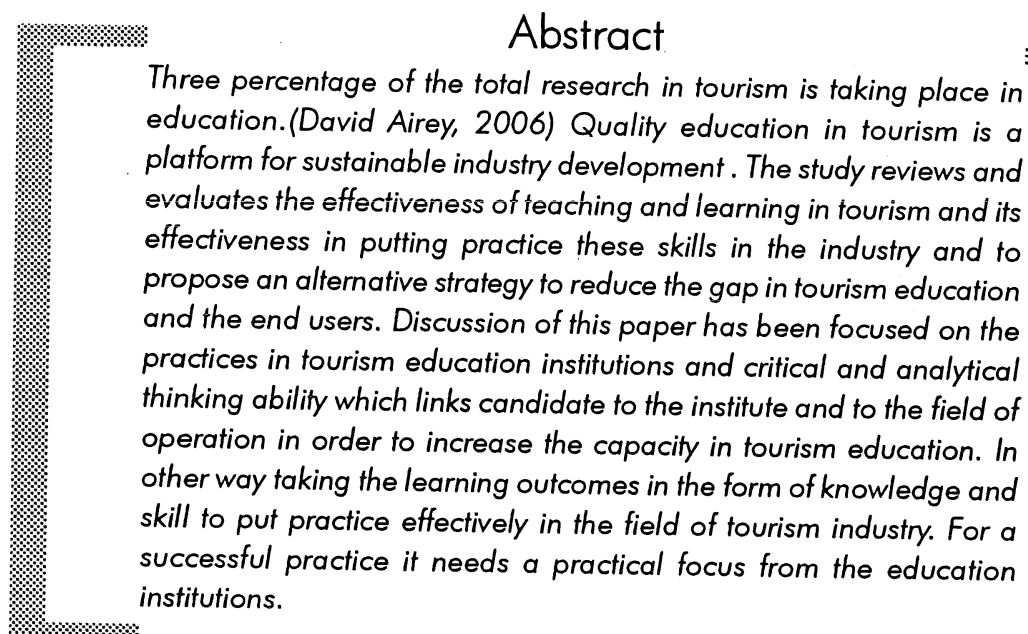

\footnotetext{
Lecturer, School of Hospitality and Tourism,Taylor's College, Level 9, Block B3, Pusat Dagang Setya Jaya (Leisure Commerce Squire), No. 9, Jalan PJS 8/9, 46150 Petaling Jaya ,Selangor, Darul Ehsan, Malaysia, Email:tonythomas@taylors.edu.my
} 


\section{Introduction}

The aim of this paper is to describe the challenges of quality education development in tourism. An education is valid only when the results tell us something about knowledge and skills, which the education purports to assure. The present tourism education system in developing countries need a reformation to achieve excellence in quality tourism education. It is very much clear that the acquired quality from tourism education is rare or very less yielded when talking about the industry experience of the candidates. Taking an example of the industry development in terms of new change in culture and educational input to meet the needs of the present industry. A big gap in this ratio can be observed in all practicing institutions. The quantity oriented and unprofessional approach and mismanagement of tourism education will be a big hurdle in the future which challenges the sustainable development of the world's largest industry.

Research in tourism education is comparatively less looking to the other arenas of tourism development. However, most of the tourism related development issue can be managed and minimized if the concentration steps into the grass root level of tourism development.

Education institutions in tourism play a vital role in the professional conduct and successful management of tourism industry. Creating professionals in tourism and stimulating motivation and skill is not achieved through a traditional education method. Tourism industry, tourists, and community are far away. Tourism trends, industry requirements and competition in the business sector makes the training institution to offer courses in a strategic way to get an accepting result and market leadership.

How these linkages could be successfully embedded in curricula and the creation of material and training program to support the quality and development of a reciprocal linkage in the beneficiaries and candidates. In the present teaching learning environment the reciprocal relationship has been shown to be most problematic (Jenkins and Zetter, 2003)

It is fair to say that no extensive consideration of the links between teaching and research in the subject has been made. What is clear form the current thinking is that linkages offer significant benefits. But they are not automatic and can in fact be problematic. (LTSN, Hospitality, Leisure, Sports and Tourism)

A particular character of the new innovative approach in tourism education is the link with the industry, to condiment the skill development among tourism 
scholars. Thus practical attachment in terms of theory oriented learning can benefit the students to accrues skills and the practicing institution can benefit and in increased output in their target. Finally the curriculum can benefit from the up-to-date material and contribution to knowledge creation.

\section{Issues in Tourism Education}

Present issues in tourism education are wider and influenced by many different internal and external factors. The professional output of candidate from different institutes can be influenced by many different factors and has been explained in figure 1. The Industry is looking for a professional approach and has to serve the organization in a well organized way, which has to meet the need of the tourists and organizations development. A mutual benefit will be asserted by both employee and employer, that conducive for the industry development. A fresh dynamic executive in tourism industry management will need a basic skill of operation, which should fuel the future management process of tourism organization.

Figure 1 Different faces of tourism education

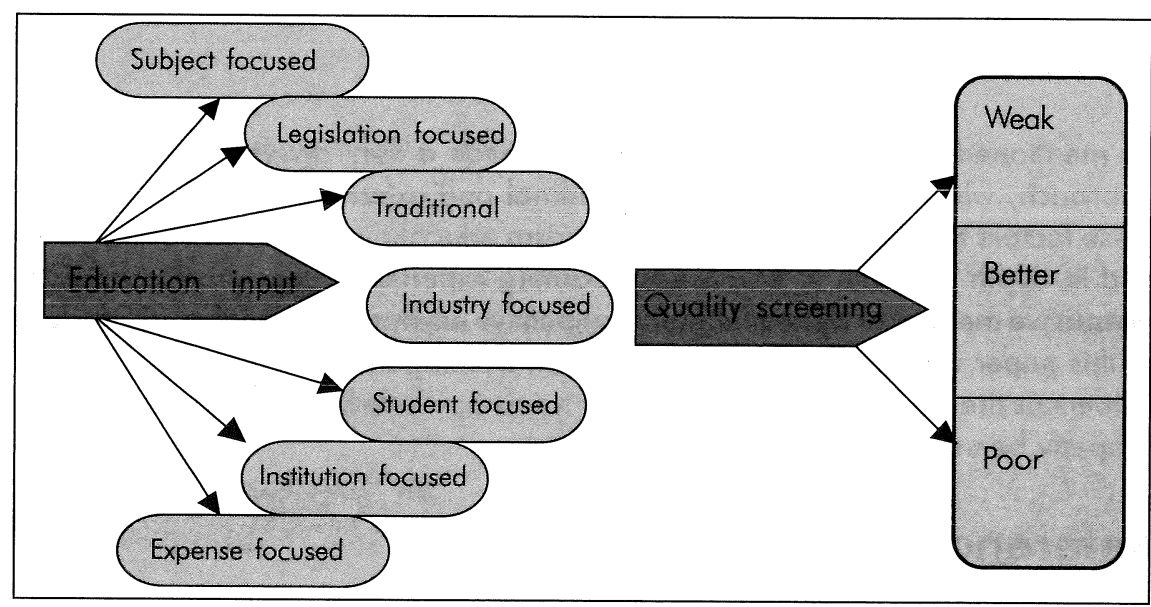

The institution organizing tourism courses are very much diverse, having different aims, focus, evaluation methods, students and faculty intake. The above diagram represents the variation in quality and performance based on the institutional policy on tourism education. Legislation interference is another critical problem. Affiliated institution has to follow up the regulation of higher body, which may not have a good concentration on tourism as a multidisciplinary subject. Traditional consideration is a hurdle for ensuring quality. Consideration of tourism 
subjects as a traditional one leading to a normal classroom teaching and partial training without having more interference with the industry create unemployables in the industry. This has multiple consequences in employment market and perception on tourism academics. Subject oriented curriculum is another hindering factor. As tourism is considered as an interdisciplinary subject, the influence of external factors like non-availability of instructors, resource materials and tools act as hindrances in the learning environment, tourism education is another issue; this is about the course design on the basis of institutions on policy, which may interact with other courses. Tourism education sometimes is forced to run with the policy of other courses. Expenses in education are considered as the most difficult factor, which create big vacums in producing quality professionals. Tourism education in a moderate financial environment is forced to withdraw many important facilities and activities. A well established library, training center and qualified professionals in the teaching learning environment would be a dream for many institutions, which neither create professionalism in the education nor give quality in performance. Subject oriented Curricula is an issue in quality tourism education. Tourism as an inter disciplinary subject need input from other discipline. Many of this input is given to the curricula according to the availability of the resource. The great effort of putting into practicing those subjects in tourism discipline is a big failure in this regard.

\section{Conclusion}

As mentioned above assuring the quality needs a very diverse and strategic approach, which influences both the internal and external factors. Framing of these factors to develop a sustainable tourism education need a thorough study and in-depth research in four areas; learning experience, teaching pedagogy, alternative method of instruction and competitive environment. Further discussion of this paper will be mostly concentrated on framing the different factors which influences the academic environments in tourism, where by the opportunity must properly be used to achieve a strong output.

\section{References}

1. David Airey and John Tribe (2005) An international handbook of Tourism Education, Elsevier, UK.

2. Chris Cooper, Rebecca Shephered and John Tribe (1994), Tourism Hospitality Education, Guildford, University of Surrey, UK.

3. J.R. Brent Ritchie and Charles R. Goeldner (2000), Travel, Tourism, and Hospitality Research (A Hand book for Managers and Researchers), Second Edition), Canada, John Wiley \& Sons.

4. Swaarbrooke.J, (1995). Tourism and Leisure education in UK. In: G. Richards (Ed), Europian Tourism and Leisure Education: Trends and Prospects. Tilberg University Press. 
5. Tribe.J Balancing the vocational: The Theory and practice of Liberal Education in Tourism. The international Journal of Tourism and Hospitality Research (The Surrey Quarterly Review), 2(1), 9 -

6. Tribe. J, (2000) The philosophic Practitioner, Annals of Tourism Research, 29 (2),338-357.

7. Tribe J, (1997), The Indiscipline of Tourism, Annals of Tourism Research, 24(3), 638-657) 